\title{
How is the surface Atlantic water inflow through the Gibraltar Strait forecasted? A lagrangian validation of operational oceanographic services in the Alboran Sea and the Western Mediterranean
}

\author{
M.G. Sotillo ${ }^{1}$, A. Amo-Baladrón ${ }^{1}$, E. Garcia-Ladona ${ }^{2}$, A. Orfila ${ }^{3}$, P. Rodríguez-Rubio ${ }^{4}$, D. \\ Conti $^{3}$, J.A. Jiménez-Madrid ${ }^{2}$, F. J. de-los-Santos ${ }^{4}$, E. Alvarez-Fanjul ${ }^{1}$
}

${ }^{1}$ Puertos del Estado. 28041 Madrid, Spain
${ }^{2}$.ICM-CSIC. 08003 Barcelona, Spain
${ }^{3}$ IMEDEA-CSIC. 07190 Esporles, Spain
${ }^{4}$.Autoridad Portuaria Bahía de Algeciras. 11207 Algeciras, Spain

\begin{abstract}
An exhaustive validation of operational ocean forecast products available in the Gibraltar Strait and the Alboran Sea is presented. The skill of two ocean model solutions (i.e. the regional CMEMS IBI and the local PdE SAMPA ones) in reproducing the complex surface dynamics in the above areas is evaluated. To this aim, in-situ measurements from 35 drifter buoys (the MEDESS-GIB database) are used as observational reference. A Lagrangian separation distance and a skill score have been applied to evaluate the performance of the modeling systems in reproducing the observed trajectories. Furthermore, the SST validation with in-situ data is carried out by means of validating the model solutions with L3 satellite SST products. The IBI products are evaluated in an extended domain, beyond the Alboran Sea, covering western Mediterranean waters. This analysis reveals some strengths of the regional solution (i.e. realistic values of the Atlantic Jet in the Strait, realistic simulation of the Algerian Current), together with some shortcomings (the major one related to the simulated geographical position and intensity of the Alboran Gyres, particularly the western one). On the other hand, the SAMPA system shows a more accurate model performance and it realistically reproduces the observed surface circulation in the area. The results reflect the effectiveness of the dynamical downscaling performed through the SAMPA system with respect to the regional IBI solution (in which SAMPA is nested), providing an objective measure of the potential added values introduced by the SAMPA downscaling solution in the Alboran Sea.
\end{abstract}

\section{INTRODUCTION}

The Gibraltar Strait is the natural connection between the Mediterranean Basin and the Atlantic Ocean and a hot spot of the world ocean, from geostrategic and scientific standpoints. The area is characterized by a very intense maritime traffic (with an estimated 100,000 ships per year) together with a noticeable port activity. All these activities together with an intense human migration entail high number of search and rescue operations in the area. It is also a high risk area in terms of oil spill events. These facts emphasise the necessity for having efficient operational oceanographic services to monitor and forecast these waters. A diagram presenting the Alboran Sea surface circulation is shown in Fig. 1 (Upper panel). The surface Atlantic water inflow through the Strait and its further flow eastward in the Alboran Sea determine the surface circulation in the area, which is characterized by very strong current regimes and complex dynamics. Dynamical downscaling from basin-scale model solution into coastal and shelf areas through nested regional model applications is nowadays a very common, but scientifically challenging approach that needs to be verified.

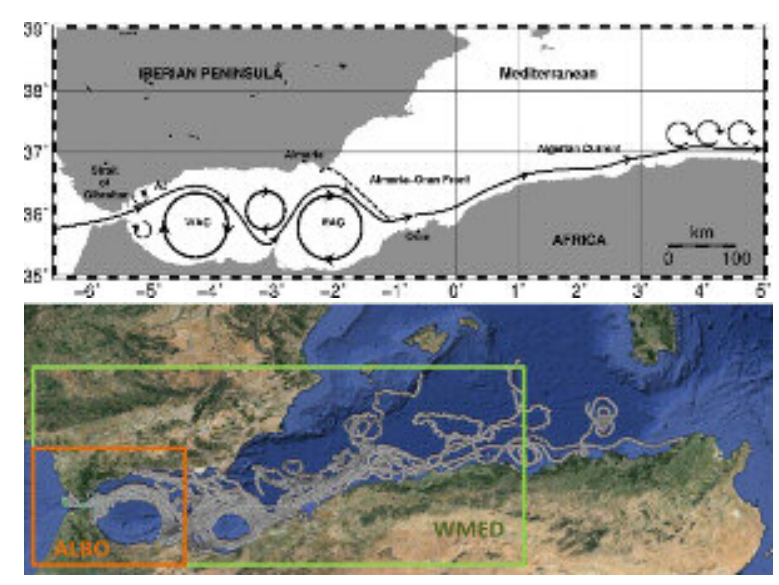

Fig. 1 Upper Panel: Scheme of surface circulation in the Alboran Sea and the Algerian Basin. Features such as the Atlantic Jet, Western and Eastern Alboran Gyres and the Algerian Current are depicted. Lower Panel: Trajectories of the MEDESS-GIB drifter buoys and geographical domains where model validation is performed.

The common Lagrangian validation framework, proposed, is useful to assess the skill of two model systems in 
simulating the surface dynamics of the area, and also provides interesting information to quantify the potential added value of the downscaled solution with respect to its parent solution (the regional one).

\section{DATA AND METHODOLOGY}

Two different surface ocean model solutions available operationally in the Gibraltar area are validated using the MEDESS-GIB data (Sotillo et al. 2016 [1]) as the observational reference. Scientific validation of modelled surface temperatures and currents delivered by the "regional" CMEMS IBI and the "local" PdE SAMPA Ocean Forecast Services has been performed for the Strait of Gibraltar and the Alboran Sea (see validation domains in Fig. 1), using different metrics and skill scores.

The Copernicus Marine Environment Monitoring Service IBI-MFC (CMEMS Monitoring \& Forecasting Centre; http://marine.copernicus.eu/) provides daily ocean model estimates and forecasts for the IBI (Iberia-Biscay-Ireland) region since 2011. The operational IBI Ocean Forecast Service is based on a NEMO model application that includes high frequency processes required to characterize regional scale marine features (further information in Sotillo et al. 2015 [2]).

On the other hand, Puertos del Estado (PdE) operationally provides from 2012 a local high resolution ocean forecast service for the Strait of Gibraltar and its surroundings (Gulf of Cadiz and Alboran Sea). The SAMPA model application was developed by the University of Malaga in collaboration with PdE and it is based on the MITGCM model. The model domain centered in the Gibraltar Strait is covered with a variable horizontal resolution (maximum resolution around $400-500 \mathrm{~m}$ in the Strait). The SAMPA model is nested into the Copernicus IBI-MFC forecast solution. SAMPA products are made available to any user through the PdE user interfaces. Further details on the SAMPA model configuration are provided in SanchezGarrido et al., 2013 [3].

\section{RESULTS AND DISCUSSION}

The present contribution show results from the exhaustive validation of two different model solutions provided by the two ocean forecast services described. Example of some lagrangian metrics for IBI and the SAMPA SST validation are shown in Fig. 2. The analysis reveals some strengths of the regional solution (i.e. realistic values of the Atlantic Jet in the Strait, realistic simulation of the Algerian Current), together with some shortcomings (the major one related to the simulated geographical position and intensity of the Alboran Gyres, particularly the western one). On the other hand, the SAMPA system shows a more accurate model performance and it realistically reproduces the observed surface circulation in the area. The results reflect the effectiveness of the dynamical downscaling performed through the SAMPA system with respect to the regional IBI solution (in which SAMPA is nested), providing an objective measure of the potential added values introduced by the SAMPA downscaling solution in the Alboran Sea.
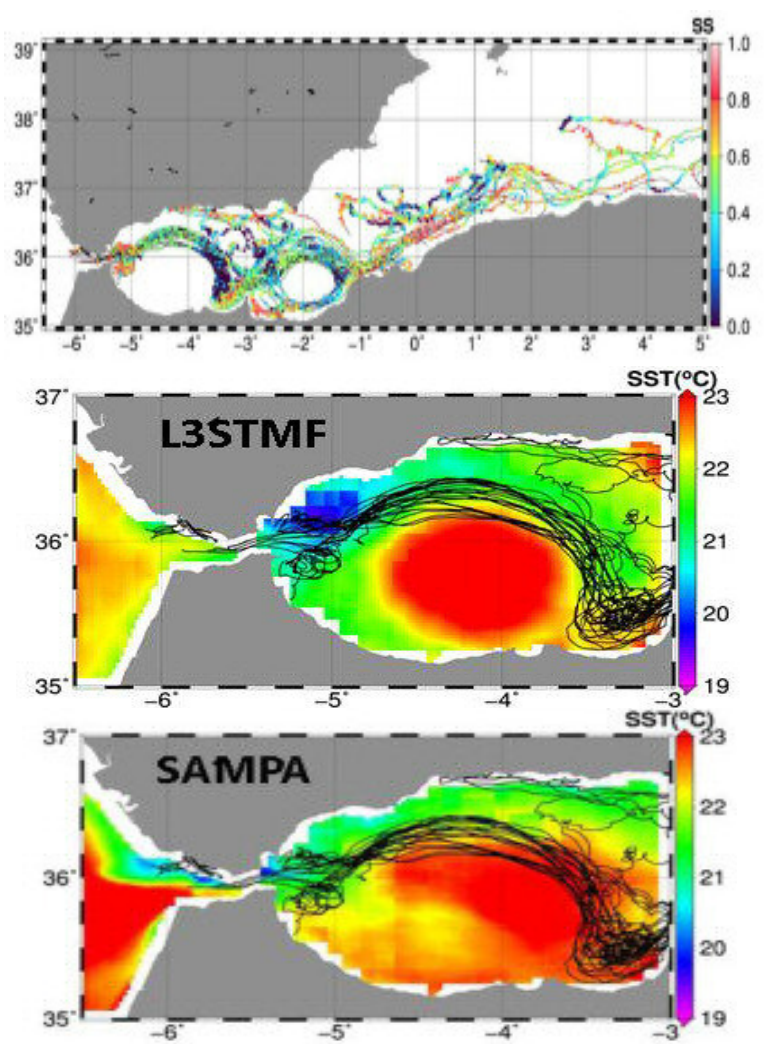

Figure 7 Example of IBI \& SAMPA validation metrics Upper panel: IBI normalized skill scores (based on Lagrangian separation distance) computed at observed MEDESS-GIB drifter locations used to initialize model virtual trajectories. 0 the poorest model quality, 1 the best agreement between model and observed trajectories. L3STMF satellite and model (SAMPA) SST averages shown in intermediate and lower panels (MEDESS-GIB buoy tracks depicted in each panel).

\section{REFERENCES}

1 - Sotillo MG, E. Garcia-Ladona, A. Orfila, P. RodríguezRubio, J. C. Maraver, D. Conti, E. Padorno, J.A. Jiménez, E. Capó, F. Pérez, J.M. Sayol, F. J. de los Santos, A. Amo, A. Rietz, C. Troupin, J. Tintore, E. Álvarez-Fanjul. (2016). The MEDESS-GIB database: Tracking the Atlantic water inflow. Earth Syst. Sci. Data, 8, 141-149, 2016 doi:10.5194/essd-8-141-2016

2 - Sotillo MG, S Cailleau, P Lorente, B Levier, R Aznar, G Reffray, A Amo-Baladrón, J Chanut, M Benkiran \& E Alvarez-Fanjul (2015): The MyOcean IBI Ocean Forecast and Reanalysis Systems: operational products and roadmap to the future Copernicus Service, Journal of Operational Oceanography,DOI:10.1080/1755876X.2015.1014663

3- Sánchez-Garrido,JC, García-Lafuente, J, Alvarez-Fanjul, E, Sotillo, MG, de los Santos, FJ, 2013. What does cause the collapse of the Western Alboran Gyre? Results of an operational ocean model, Progress in Oceanography, 116,142-53 http://dx.doi.org/10.1016/j.pocean.2013.07.002 